Clin. Path., 1977, 30, 144-150

\title{
25-Hydroxyvitamin D levels in patients treated with high-dosage ergo- and cholecalciferol
}

\author{
J. M. GERTNER ${ }^{1}$ AND MERCEDES DOMENECH ${ }^{2}$
}

From the Department of Human Metabolism, University College Hospital Medical School, London

SUMmaRY 25-Hydroxyvitamin D (25-OHD) levels were measured in 39 patients with metabolic bone disease or hypoparathyroidism who had been treated with a constant high dose of vitamin $\mathrm{D}_{2}$ or $\mathrm{D}_{3}$ for at least 12 weeks. Plasma 25-OHD levels rose with increasing dosage, the relationship between dose and plasma level being approximately linear whether or not the dose was expressed on a weight-corrected basis. A therapeutic range of 25-OHD to be expected when patients with these conditions are treated with vitamin $\mathrm{D}$ has been established. There may be certain exceptions in which plasma 25-OHD levels within this range are associated with either an inadequate response to treatment or, conversely, the hypercalcaemia of vitamin D toxicity.

There was no correlation between plasma calcium level and 25-OHD concentration in the group of patients studied. There was also no difference between the dose/25-OHD relationship of patients treated with vitamin $D_{2}$ and that of patients receiving vitamin $D_{3}$.

Ten patients were started on treatment with large doses of vitamin $\mathrm{D}$ during the period of the study. The rate of rise of plasma 25-OHD was followed during treatment. The incremental rise in 25-OHD was calculated at the end of the first week of treatment in terms of dose per unit body weight. The rate of rise of plasma 25-OHD level was highly correlated with the dose used. Plasmax 25-OHD levels after one week's treatment were only $15-20 \%$ of the expected steady-state level on the same dosage. The importance of a high priming dose when a rapid response is needed is thus emphasised.

The availability of a precise and convenient assay for 25-hydroxyvitamin $\mathrm{D}$ has yielded important information bearing on many aspects of metabolic bone disease (Haddad and Stamp, 1974; Offermann et al., 1974; Preece et al., 1975). These assays measure the compound formed by hepatic 25hydroxylation of vitamin D. 25-OHD is normally the major component of the antirachitic activity of the plasma (Edelstein et al., 1974), and its plasma level reflects the vitamin D nutritional status of the subject.

Assays of plasma levels of drugs or their metabolites have become increasingly important in pharmacology and in practical therapeutics. The aim of the present study was to determine the relationship between doses of vitamin $\mathbf{D}$ given to patients with metabolic bone disease or hypo-

\footnotetext{
Present addresses: 'Queen Elizabeth Hospital for Children. Hackney Road, London E2 8PS.

¿Catedra de Pediatria Puericultura, Faculdad de Medicina, Universidad de Valencia, Spain

Received for publication 9 June 1976
}

parathyroidism and the plasma concentrations of 25-OHD. In this way we hoped to derive information on the pharmacokinetics of vitamin $\mathbf{D}$ and to establish expected plasma values that would be of use in monitoring treatment and investigating unexpected responses to therapy.

\section{Patients and methods}

All patients currently attending the outpatient clinics of the Department of Human Metabolism o who received constant high doses of vitamin $\mathbf{D}_{2}$ or $D_{3}$ for at least 12 weeks were included in the first part of the study. 'High dose' in this sense was taken to mean more than $0.125 \mathrm{mg} /$ day (5000 iu vitamin $\mathrm{D} /$ day). Patients with simple vitamin $\mathrm{D}$ c0 deficiency due to poor diet or lack of exposure to sunlight were not included in the study.

The diagnoses represented in the sample are shown in Table 1.

Sixteen of the patients were prepubertal children (aged 6 months to 12 years) while the remainder $\stackrel{D}{\circ}$ 
Table 1 Primary diagnosis of patients in the study

\begin{tabular}{lr}
\hline Diagnosis & No. \\
\hline Osteomalacia after gastrectomy & 2 \\
Sex-linked hypophosphataemic rickets & 10 \\
Fanconi syndrome & 6 \\
Adult presenting hypophosphataemic osteomalacia & 5 \\
Other types of rickets and osteomalacia & 3 \\
Osteoporosis & 5 \\
Hypoparathyroidism & 6 \\
Others & 2 \\
Total & 39 \\
\hline
\end{tabular}

were adults aged 18 to 71 years. The male: female ratio was $12: 4$ for the children and 10:13 for adults.

Ten patients started on high-dose vitamin D therapy during the period of the study; 25-OHD levels were measured at intervals after the start of treatment, and detailed analyses of the situation after one week of treatment are presented.

The vitamin D used was dispensed by the $\mathrm{UCH}$ pharmacy in all but two cases. The oily solution is prepared in UCH by the method described by Dent and Friedman (1964) to ensure precision of dose. Commercially available vitamin $\mathrm{D}$ preparations are permitted to vary in strength by up to $35 \%$.

Plasma 25-OHD was measured by the method of Haddad and Chyu (1971) with modifications by Stamp (1972). This method is equally sensitive to 25-OHD 2 and $25-\mathrm{OHD}_{3}$.

The coefficient of variation of 25-OHD levels in reference plasma between assays was $9.9 \%$. The recovery of non-radioactive 25-OHD added to reference plasma before extraction was $108 \pm 9 \%$.

Plasma calcium was measured by flame emission spectrophotometry and corrected for plasma specific gravity by the method of Dent (1962).

\section{Results}

Thirty-nine patients received vitamin $\mathrm{D}$ for at least 12 weeks in doses ranging from 0.125 to $2.5 \mathrm{mg} /$ day. Their 25-OHD levels plotted in terms of absolute dosage are shown in Fig. 1. An approximately linear relationship between dose and plasma level is apparent $(r=0.83 ; P<0.01 ; n=39)$.

Six patients had been treated with vitamin $D$ for between 12 and 26 weeks and one for between 26 and 52 weeks. These are identified by square symbols in Fig. 1. It can be seen that the patients treated for shorter periods do not differ appreciably from the majority in their dose/plasma level relationship.

Plasma 25-OHD levels are plotted against dose per unit body weight in Fig. 2. Here again there appears to be a linear relationship between dosage and plasma concentration $(r=0.68 ; \quad P<0.01$; $n=34$ ). This calculation excludes five patients whose plasma levels were much lower than would be expected from the data derived from the other 34 patients. The five excluded were all small children (mean weight $10 \cdot 3 \mathrm{~kg}$ ).

Only seven of the 39 patients were treated with vitamin $D_{3}$. The dosage used and the corresponding 25-OHD and calcium levels in the plasma are shown in Table 2. When these seven patients are compared to the group as a whole there is no significant difference in the relationship of plasma 25-OHD to vitamin D dose administered, nor is

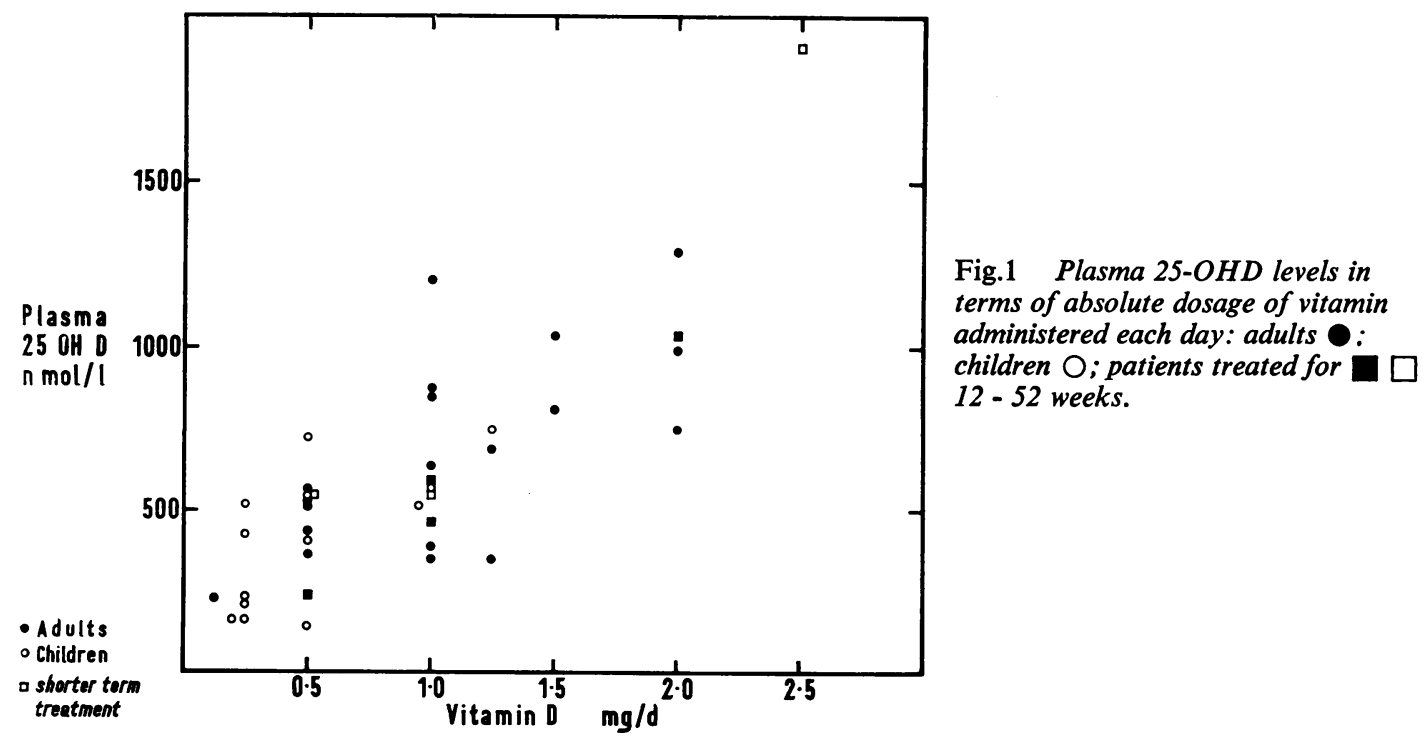

Fig.1 Plasma 25-OHD levels in terms of absolute dosage of vitamin administered each day: adults 0 : children $\bigcirc$; patients treated for $\square \square$ 12 - 52 weeks. 


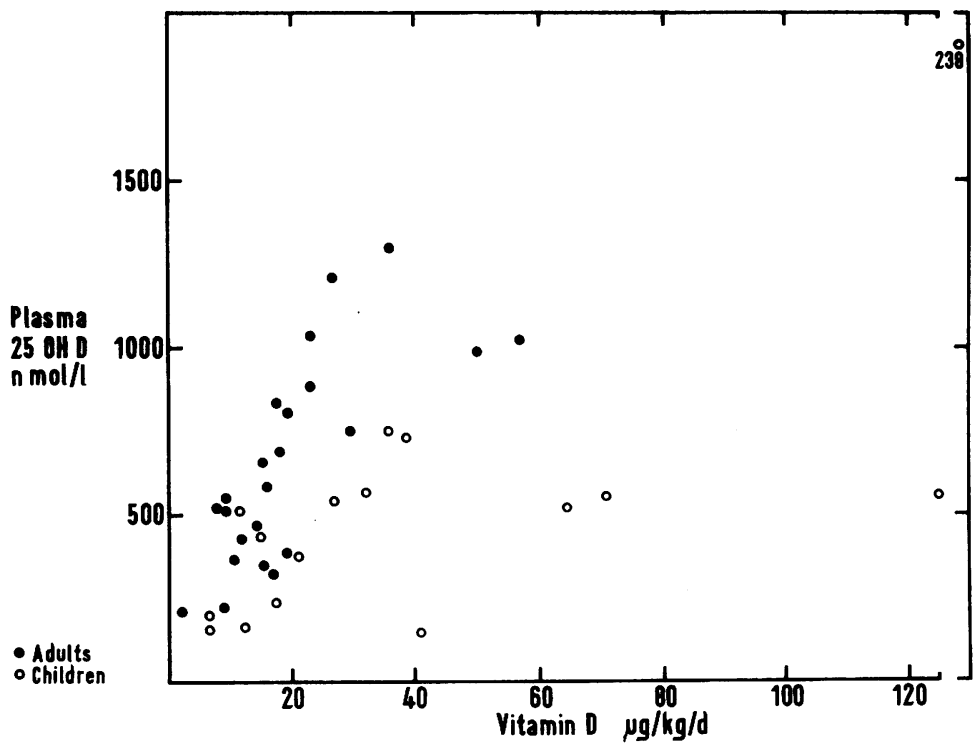

Fig. 2 Plasma 25-OHD levels in terms of weight-adjusted dose of vitamin. Data from five children are not included in the calculation of regression (see text).

Table 2 Details of patients treated with vitamin $D_{3}$

\begin{tabular}{llll}
\hline $\begin{array}{l}\text { Dose of vitamin } \\
\text { D, (mg/day) }\end{array}$ & $\begin{array}{l}\text { Dose (weight-adjusted) } \\
(\mu g / k g / d a y)\end{array}$ & $\begin{array}{l}25-\mathrm{OHD} \\
(\mathrm{nmol} / \mathrm{l})\end{array}$ & $\begin{array}{l}\text { Plasma Ca } \\
(\mathrm{mmol} / \mathrm{l})\end{array}$ \\
\hline 1 & 19.5 & 397 & 2.52 \\
0.5 & 9.1 & 512 & 2.50 \\
0.5 & 7.9 & 518 & 2.55 \\
0.5 & 40.7 & 148 & 2.40 \\
1.5 & 19.5 & 808 & 2.22 \\
0.5 & 9.1 & 553 & 2.50 \\
1 & 23 & 880 & 2.50
\end{tabular}

Neither plasma 25-OHD concentration in terms of dose per unit body weight nor plasma calcium in terms of plasma 25-OHD concentration differ substantially from the group as a whole.

there any difference in the relationship of plasma calcium to 25-OHD level.

For the purposes of comparison with the patients in the study who required high doses of vitamin $D$, the plasma levels of four patients with nutritional rickets and one with osteoporosis, all taking 'physiological' doses of vitamin $\mathrm{D}$, are shown in Table 3. The plasma 25-OHD level lies within or just above

Table 3 Details of patients on long-term low-dose vitamin $D$ supplementation (normal range for plasma 25-OHD 25-88 nmol/l)

\begin{tabular}{rllll}
\hline Age & Sex & Diagnosis & $\begin{array}{l}\text { Vitamin D } \\
\text { dose } \\
(\mu g / \text { kg/day })\end{array}$ & $\begin{array}{l}25-\text { OHD } \\
(\text { nmolll })\end{array}$ \\
\hline 9 & F & A & $1 \cdot 1$ & 191 \\
8 & F & A & $1 \cdot 2$ & 70 \\
15 & M & A & 0.7 & 55 \\
31 & F & A & $0 \cdot 2$ & 60 \\
64 & F & A & 0.7 & 80 \\
48 & F & B & 0.6 & 105 \\
\hline
\end{tabular}

A-nutritional rickets and osteomalacia; B-osteoporosis

${ }^{1}$ Measured in February when levels tend to be at their lowest the normal range for the general population in ale these patients.

Plasma 25-OHD levels from the 10 patients who were started on high-dose vitamin $\mathbf{D}$ treatment were measured at various intervals after the start of 蒠e treatment. Unfortunately the only time interval $\#$ t which data from all these patients are available is on week after starting treatment. The details of dosageo 25-OHD level, and time at which the plasma was examined are shown in Table 4. Figure 3 shows th $\overrightarrow{5}$ incremental rise in plasma 25-OHD level plotted against the dose per unit body weight for these 19 patients. The rise in 25-OHD is significantly cor? related to the dose administered $(r=0.79 ; P<0.01$ $\mathrm{n}=9$ ). The point corresponding to the incrementa: rise in 25-OHD after one week for the tenth patien $\overline{\mathrm{B}}$. is shown on the figure but his data are not included in the calculation of correlation as his dose was changed before the blood level was measured. His ascribed dose, in Fig. 4, is the mean daily dose for this patient.

Plasma calcium (corrected for specific gravity was not significantly correlated with $25-\mathrm{OHD}$ levêt $(r=0 \cdot 12 ; P>0 \cdot 1 ; n=38)$ (see Fig. 4).

\section{Discussion}

Our study involved an examination of the relation ship between dosage with vitamin $D$ and circulating concentrations of the first metabolite of that vitamin along the sequence in which vitamin $D$ is activated. Because the necessary assay technique are far less sensitive or, as yet, not readily availablo we did not attempt to measure levels of vitamin 


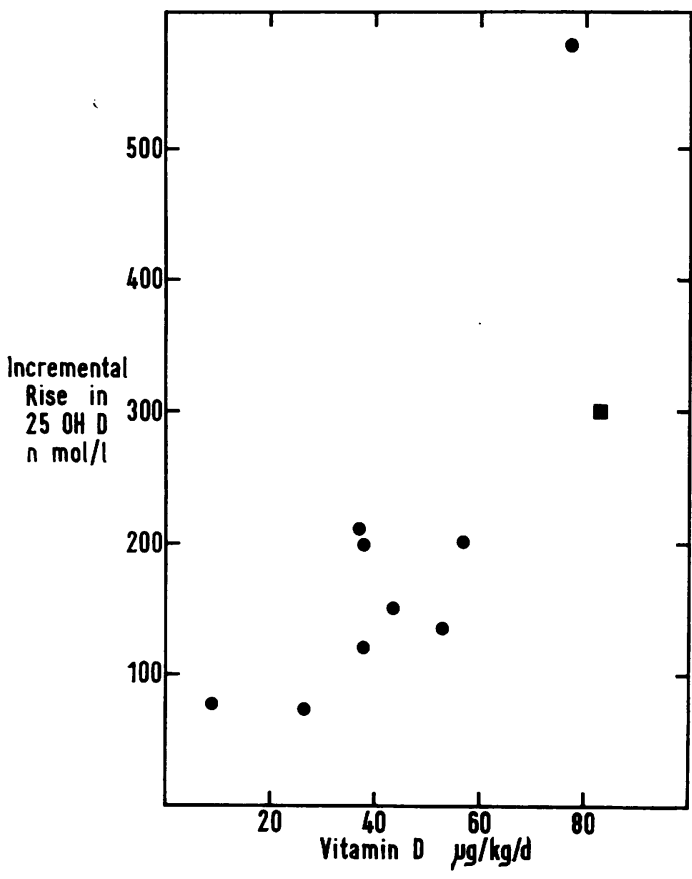

Fig. 3 Incremental rise in 25-OHD levels after one week's treatment in terms of weight-adjusted dose. Data from Table 4.

Denotes patient not included in calculation of regression (see text).

itself or of the active metabolite, 1:25 dihydroxyvitamin $D$ (1:25 diOHD). Thus a pharmacokinetic approach to the analysis of our data is extremely complicated, some of the factors involved being represented in Fig. 5.

Various authors have studied 25-OHD levels in untreated patients suffering from metabolic bone disease, especially rickets and osteomalacia (Preece et al., 1975). There have also been extensive surveys of normal persons and groups thought to be 'at risk' for vitamin D deficiency states (Stamp et al., 1972; Corless et al., 1975). The rate of rise of 25OHD level in a subject on a constant dose of vitamin D has been examined by Haddad and Stamp (1974). Bioassay techniques have been used to measure the vitamin $\mathbf{D}$ activity in humans treated with large doses of vitamin D (Warkany et al., 1942; Lumb et al., 1971), while one study reported briefly on 25-OHD levels in a group of patients receiving long-term treatment with high doses of vitamin D (Haddad and Stamp, 1974). 25-OHD levels in sporadic cases of vitamin $\mathbf{D}$ intoxication have been reported by a few authors (Preece et al., 1975; Counts et al., 1975).

The present report concerns patients whose therapy required high doses of vitamin $D$ ranging from 0.125 to $2.5 \mathrm{mg} /$ day. We have shown that over this dose range, corresponding to a weight-corrected dose of $8-40 \mu \mathrm{g} / \mathrm{kg} /$ day, plasma $25-\mathrm{OHD}$ concentration is highly correlated with the dose of vitamin $\mathbf{D}$ administered. A linear relationship between 25-OHD concentration and size of dose is reached within three months of starting treatment.

Over this dose range, therefore, plasma 25-OHD measurements suggest that an equilibrium is reached, at least as far as plasma levels are concerned. This finding may be contrasted with the observations of

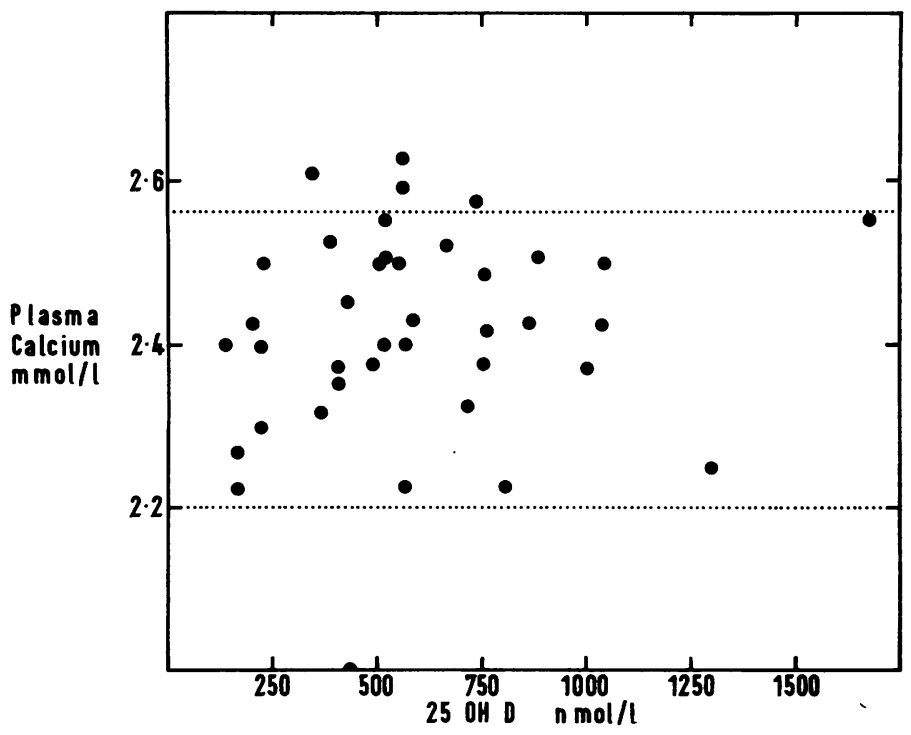

Fig. 4 Plasma calcium (corrected for plasma specific gravity) in terms of plasma 25-OHD levels. Normal range 2.20-2.57 mmol/l shown by dotted lines. 
Table 4 Details of nine patients starting treatment with high doses of vitamin D

\begin{tabular}{|c|c|c|c|c|c|c|c|c|c|}
\hline \multirow[t]{2}{*}{ Diagnosis } & \multicolumn{9}{|l|}{ Patient } \\
\hline & $\begin{array}{l}1 \\
\text { Post } \\
\text { gastrectomy } \\
\text { OM }\end{array}$ & 2 & $\begin{array}{l}3 \\
\text { Nutritional } \\
\text { OM }\end{array}$ & $\stackrel{4}{A H O M}$ & $\begin{array}{l}5 \\
\text { Osteoporosis }\end{array}$ & 6 & $\begin{array}{l}7 \\
\text { Nutritional } \\
\text { OM }\end{array}$ & $\begin{array}{l}8 \\
\text { Hypopara- } \\
\text { thyroidism }\end{array}$ & $\begin{array}{l}9 \\
\text { Post } \\
\text { gastrectomy } \\
\text { OM }\end{array}$ \\
\hline $\begin{array}{l}\text { 25-OHD levels: } \\
\text { Before } \\
\text { treatment }\end{array}$ & 30 & 25 & $2 \cdot 5$ & 75 & $17 \cdot 5$ & 25 & 5 & 65 & 5 \\
\hline On treatment & 165 & 225 & 122 & 658 & 95 & 165 & 157 & 135 & 340 \\
\hline $\begin{array}{l}\text { Treatment days } \\
\text { before } 2 \text { nd } \\
\text { measurement }\end{array}$ & 7 & 7 & 7 & 7 & 7 & 5 & 7 & 7 & 12 \\
\hline $\begin{array}{l}\text { Rate of rise } \\
\text { (nmol/1/week) }\end{array}$ & 135 & 200 & 120 & 582 & 78 & 210 & 152 & 70 & 195 \\
\hline $\begin{array}{l}\text { Dose of vitamin } \\
\text { D (mg/day) }\end{array}$ & 2 & 2 & 2 & 5 & 0.5 & 2 & 2 & 2 & 2 \\
\hline Weight corrected & 53 & 38 & 38 & 77 & $9 \cdot 1$ & 36 & 43 & 27 & 57 \\
\hline
\end{tabular}

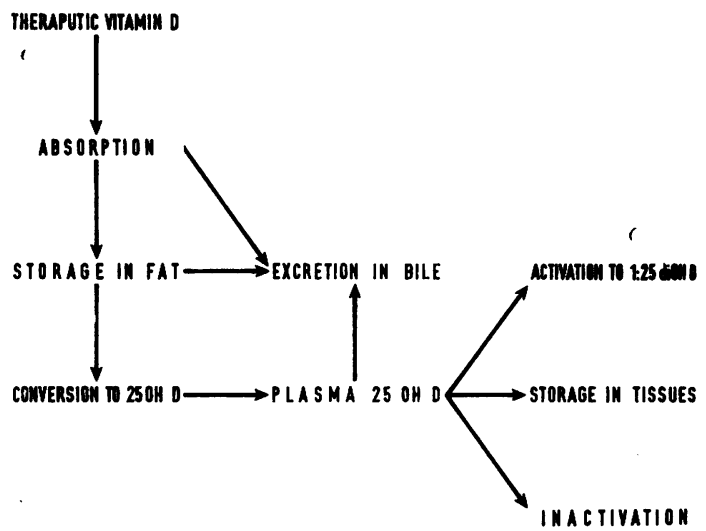

Fig. 5 Scheme of possible pathways taken by ingested vitamin $D$ and its metabolites.

Mawer et al. (1972), who found that vitamin D continued to be taken up into the fat stores of patients who had been given high doses of the vitamin for prolonged periods.

We do not observe any marked tendency for feedback regulation of the rate of conversion of 25-OHD as dose levels increase. At higher doses, however (greater than $35 \mu \mathrm{g} / \mathrm{kg} /$ day), it does appear possible that incremental rises in the dosage of vitamin $D$ produce somewhat smaller rises in 25-OHD levels although the data for these high doses are rather scanty.

Inspection of Fig. 2 suggests reduced plasma levels of 25-OHD for a given weight-corrected dose in children as compared with adults. This might imply reduced rates of hepatic 25-hydroxylation of vitamin $D$ or increased rates of elimination of 25-OHD. Detailed statistical analysis of the data, however, does not demonstrate a convincing significant difference between the two age groups.
Further study of this question is needed before any을 firm conclusions can be drawn.

The plasma 25-OHD levels found in most patients in the study can be held to represent the therapeutic range for the type of case in which high dose therapy is used. It might be expected that inade- quately treated patients would be hypocalcaemic or have active rickets or osteomalacia. Active rickgts was observed in only three of our series, all childrent? with cystinosis, whose 25-OHD levels were 148, 520 , and $563 \mathrm{nmol} / \mathrm{l}$ respectively. All these patient 5 were also in the group whose 25-OHD levels were口 lower than expected from their weight-correctec $B$ vitamin dosage (Fig. 2). It seems as though these children need higher plasma 25-OHD levels to maintain their rickets in remission than other patients with resistant rickets and oesteomalacia? The reason for this is obscure. One child with hypoparathyroidism had a subnormal plasm calcium $(2.0 \mathrm{mmol} / \mathrm{l})$ despite a $25-\mathrm{OHD}$ level of $548 \mathrm{nmol} / 1$. The other treated hypoparathyroids patients were normocalcaemic.

None of the patients studied was suffering from chronic vitamin $\mathbf{D}$ overdosage as evidenced by serious hypercalcaemia. Indeed, only four patients plasma calcium levels were above the upper limit of normal. All of these were patients with severf hypophosphataemia (two sex-linked and two adult presenting). Their plasma 25-OHD levels ranged fron 350 to $725 \mathrm{nmol} / \mathrm{l}$, by no means the highest in the series. It is tempting to speculate that these patients are made more sensitive to a given plasma level of 25-OHD by the increased conversion rate of 25-OHD to $1: 25$ diOHD consequent upon their reduced intercellular phosphate concentration as suggested. by DeLuca (1973).

The therapeutic range of 25-OHD in our patients? representing a number of diagnoses all needing 
high-dose treatment with vitamin $\mathrm{D}$, lay between 188 and $1250 \mathrm{nmol} / 1$. As mentioned above, only three patients with cystinosis and one with hypoparathyroidism showed signs of undertreatment while none was suffering from significant overdosage. This information should offer clinicians treating patients with high doses of vitamin $\mathrm{D}$ an additional means of assessing the effects of treatment and of investigating patients showing unexpected responses to such treatment. Thus hypercalcaemia due to vitamin $\mathrm{D}$ intoxication should be associated with levels greater than 1000-1250 nmol/1 (possibly lower in some hypophosphataemic patients). Conversely, treatment failure might be associated with plasma 25-OHD levels lower than expected and probably below $250 \mathrm{nmol} / \mathrm{l}$. In theory such low levels could be due to malabsorption, reduced hepatic conversion to 25-OHD, or increased breakdown rates of this compound but in practice failure to take the medication in adequate dosage as prescribed will probably account for many such cases. The only subject in our series whose plasma 25-OHD level was plainly lower than expected readily conceded that he did not always take all his tablets. His plasma 25-OHD levels rose from 93 to $350 \mathrm{nmol} / \mathrm{l}$ over a three-month period although he was supposed to have been on a steady dose of vitamin $D_{2}(1 \mathrm{mg} /$ day $)$ for over a year before the first measurement was made.

Our data relating the rate at which plasma 25 OHD levels rise with the onset of treatment accord with clinical experience. It is plain that we are dealing with a substance whose rates of accumulation in the body and eventual elimination are slow. Because of the complexity of the interrelated pathways of storage, metabolism, and excretion of these substances no attempt has been made to calculate accumulation or elimination rates for vitamin D or 25-OHD.

In a group of 10 patients plasma 25-OHD levels were measured as they started treatment with vitamin $\mathrm{D}$. There was an apparent linear relationship between weight-adjusted dose and incremental rise in 25-OHD over the first week $(r=0.79$; $\mathbf{P}<0.01 ; \mathrm{n}=9$ ). Thus over the dose range studied the rate of rise of 25-OHD was proportional to the weight-adjusted dosage and there was no evidence that saturation of the capacity to convert vitamin $\mathrm{D}$ to 25-OHD had occurred.

Comparing the slope of the regression line for rate of rise of 25-OHD against dose (Fig. 4) with that in Fig. 2, we find that at a dose of $30 \mu \mathrm{g} / \mathrm{kg} / \mathrm{day}$ the rise in plasma 25-OHD level after one week is only $15-20 \%$ of that after a steady state has been reached. The implication is that very much larger priming doses should be used to raise plasma levels of 25-OHD rapidly into the therapeutic range when this is necessary. From Fig. 4 it seems that the mid-therapeutic range $(500 \mathrm{nmol} / \mathrm{l})$ is reached after one week on a vitamin D dosage of $60 \mu \mathrm{g} / \mathrm{kg} /$ day (over $4 \mathrm{mg}$ or $160000 \mathrm{iu} /$ day for a $70 \mathrm{~kg}$ man). This slow onset of action of vitamin $\mathbf{D}$ and the need for priming doses much higher than the eventual maintenance doses are well recognised clinically and are now seen to have a basis in the slow build-up of 25-OHD levels even when relatively high treatment doses are given.

The measurement of 25-OHD has now become an essential technique in the investigation and treatment of patients with metabolic bone disease and hypoparathyroidism. Evaluation of therapeutic response, detection of inadvertent overdosage, and examination of patient compliance with treatment regimes can be added to the list of applications to which the assay may be put. Naturally these measurements apply only to vitamin $D$ analogues which do raise the plasma 25-OHD level, namely, cholecalciferol, ergocalciferol, and 25-OHD itself. The ability to relate circulating 25-OHD levels to dosage and activity when these compounds are used may, in some circumstances, be a consideration leading to their use in preference to dihydrotachysterol and 1-alpha-hydroxycholecalciferol, which do not elevate plasma 25-OHD levels while exerting their vitamin D-like activity and for which no assay is yet readily available.

We wish to thank Professor C. E. Dent for encouraging us to undertake this project, for permission to study his patients and for his helpful advice.

We are grateful for the advice and helpful comments on the manuscript received from Dr D. P. Brenton.

We thank Miss Joan Round, principal biochemist, and her staff for performing the plasma calcium estimations.

The work was financed by an MRC project grant.

\section{References}

Corless, D., Boucher, B. J., Cohen, R. D., Beer, M., and Gupta, S. P. (1975). Vitamin-D status in long-stay geriatric patients. Lancet, 1, 1404-1406.

Counts, S. J., Baylink, D. J., Shen, F. H., Sherrard, D. J., and Hickman, R. O. (1975). Vitamin D intoxication in an anephric child. Annals of Internal Medicine, 82, 196-200.

DeLuca, H. F. (1973). The kidney as an endocrine organ for the production of 1,25-dihydroxyvitamin $D_{3}$, a calciummobilizing hormone. New England Journal of Medicine, 289, 359-365.

Dent, C. E. (1962). Some problems of hyperparathyroidism. British Medical Journal, 2, 1419-1425.

Dent, C. E., and Friedman, M. (1964). A comparison between A.T.10 and pure dihydrotachysterol in control- 
ling hypoparathyroidism. Lancet, 2, 164-169.

Edelstein, S., Charman, M., Lawson, D. E. M., and Kodicek, E. (1974). Competitive protein-binding assay for 25hydroxycholecalciferol. Clinical Science and Molecular Medicine, 46, 231-240.

Haddad, J. G., and Chyu, K. J. (1971). Competitive proteinbinding radioassay for 25 -hydroxycholecalciferol. Journal of Clinical Endocrinology and Metabolism, 33, 992-995.

Haddad, J. G., and Stamp, T. C. B. (1974). Circulating 25-hydroxyvitamin $D$ in man. American Journal of Medicine, 57, 57-62.

Lumb, G. A., Mawer, E. B., and Stanbury, S. W. (1971). The apparent vitamin $D$ resistance of chronic renal failure. American Journal of Medicine, 50, 421-441.

Mawer, E. B., Backhouse, J., Holman, C. A., Lumb, G. A., and Stanbury, S. W. (1972). The distribution and storage of vitamin $\mathrm{D}$ and its metabolites in human tissues. Clinical Science and Molecular Medicine, 43, 413-431.
Offermann, G., von Herrath, D., and Schaefer, K. (1974). Serum 25-hydroxycholecalciferol in uremia. Nephron, 13, 269-277.

Preece, M. A., Tomlinson, S., Ribot, C. A., Pietrek, J., Korn, H. T., Davies, D. M., Ford, J. A., Dunnigan, M. G., and O'Riordan, J. L. H. (1975). Studies of vitamin D deficiency in man. Quarterly Journal of Medicine, 44, 575-589.

Stamp, T. C. B. (1972). Unpublished.

Stamp, T. C. B., Round, J. M., Rowe, D. J. F., and Haddad J. G. (1972). Plasma levels and therapeutic effect of $\omega$ 25-hydroxycholecalciferol in epileptic patients taking $\vec{\circ}$ anticonvulsant drugs. British Medical Journal, 4, 9-12.

Warkany, J., Guest, G. M., and Grabill, F. J. (1942). Estimation of vitamin D in blood serum. Vitamin D in human serum during and after periods of ingestion of large doses of vitamin D. Journal of Laboratory and Clinical Medicine, 27, 557-565. 